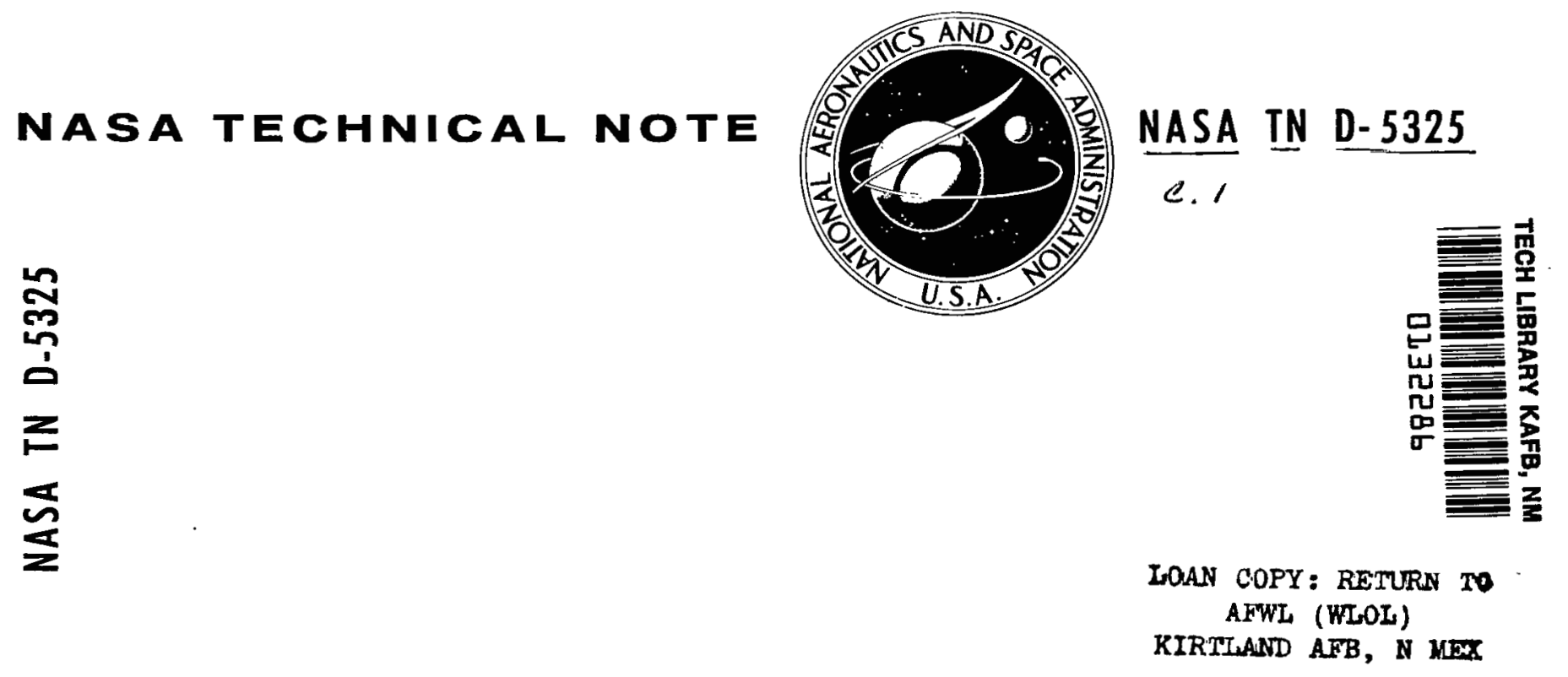

\title{
A MINIATURE TWO-AXIS FLUXGATE MAGNETOMETER
}

by

C. J. Pellerin

Goddard Space Flight Center and

M. H. Acuña

Fairchild Hiller Corporation 


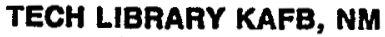

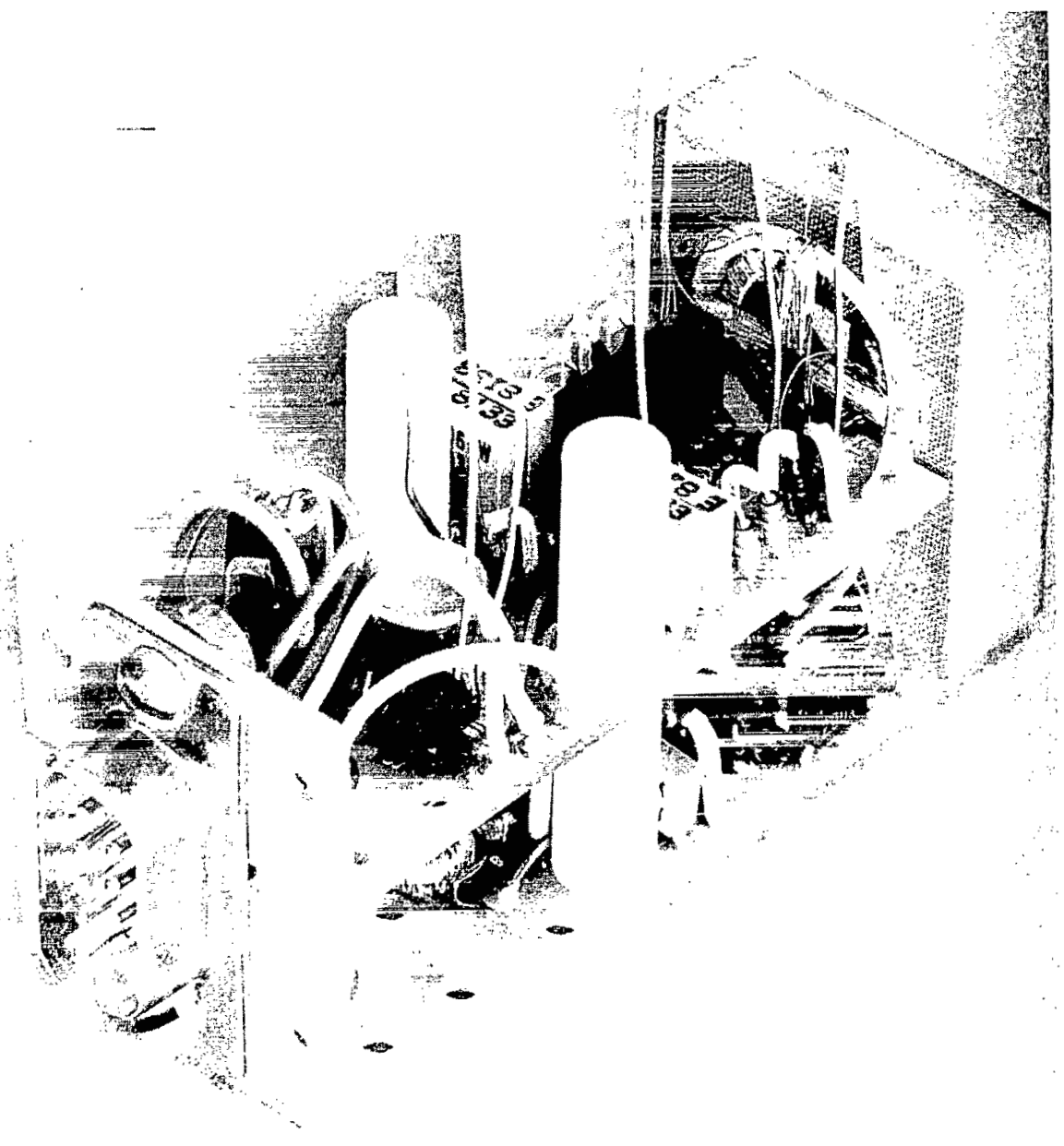

Frontispiece-The two-axis magnetometer. 
1. Report No. NASA TIN D-5325

4. Title and Subtitle

A Miniature Two-Axis Fluxgate Magnetometer

7. Author(s)

C. J. Pellerin and M. H. Acuña

9. Performing Organization Name and Address

Goddard Space Flight Center

Greenbelt, Maryland 20771

12. Sponsoring Agency Nome and Address

National Aeronautics and Space Administration

Washington, D. C. 20546

15. Supplementary Notes
3. Recipient's Catalog No.

5. Report Date

January 1970

6. Performing Organization Code

8. Performing Organization Report No. $\mathrm{G}-944$

10. Work Unit No. 879-70-01-03-51

11. Controct or Grant No.

13. Type of Report and Period Covered Technical Note

14. Sponsoring Agency Code

16. Abstract

A miniature two-axis fluxgate magnetometer for sounding rocket applications has been developed. The distinctive feature of this instrument is that it simultaneously measures, with a single sensing element, two orthogonal components of an external magnetic field. Observed performance is accurately predicted by means of a quantitative linear mathematical model. The dependence of the output voltage on several design parameters is obtained by a Fourier analysis of the output waveform. A computer-aided analysis is presented for core materials of 4-79 Mo-Permalloy and 50-50 Ni-Fe.

17. Key Words Suggested by Author

18. Distribution Statement Magnetometer Unclassified-Unlimited

Miniature Magnetometer Two-Axis Magnetometer Sounding Rockets-Instrumentation

19. Security Classif. (of this report) 20. Security Clossif. (of this page)
(20) Unclassified Unclassified

21. No. of Pages 23
22. Price *

$\$ 3.00$ 

CONTENTS

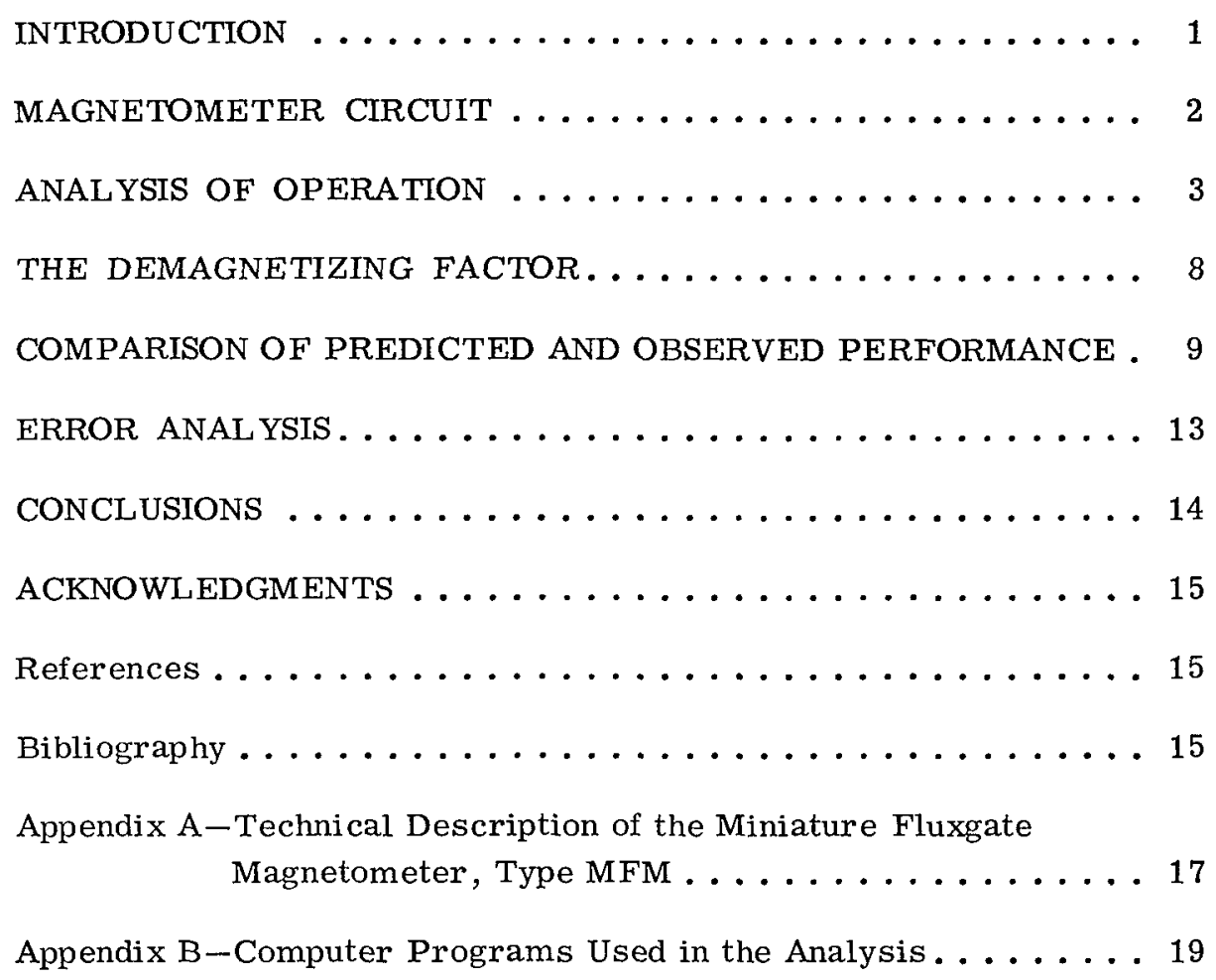




\title{
A MINIATURE TWO-AXIS FLUXGATE MAGNETOMETER*
}

\author{
by \\ C. J. Pellerin \\ Goddard Space Flight Center \\ and \\ M. H. Acuña \\ Fairchild Hiller Corporation
}

\section{INTRODUCTION}

Ring-core magnetometers have been extensively used for magnetic measurements since their introduction in 1961 by W. A. Geyger (References 1 and 2). In general, the operating frequency of these instruments has been relatively low ( 5 to $10 \mathrm{kHz}$ ), and they have had only single-axis sensing capabilities because of the large number of turns required in the pickup winding. However, the ring-core geometry is ideally suited to multiple-axis sensing applications where the orientations of the sensing axes are parallel to the plane of the core. Gordon et al. (Reference 3) discussed the fundamental factors affecting the operation of ring-core magnetometers for different types of drive waveforms, and set forth criteria for selection of core materials, geometric factors, and operating frequency.

This paper is an extension of that study, applied to the case of a two-axis core magnetometer operating at a much higher frequency and of comparatively smaller size. A linear mathematical model has been developed where the hysteresis loop of the core material is idealized by assuming constant slopes for the different regions, and is justified by comparison of the predicted and observed performance.

This magnetometer provides two orthogonal measurements of an external magnetic field. In cases where the external field components are known from spherical harmonic expansions, the data obtained are sufficient to determine magnetic aspect as well as roll rates and approximate pitch angles. This is the primary application intended for the instrument. However, because of the high sensitivity $(1 \mathrm{mv} / \gamma)$ and low construction cost, the instrument has wide application in geomagnetic field sensing.

Although this paper is primarily concerned with a two-axis magnetometer, the extension to a three-axis magnetometer is quite simple. Laboratory prototypes have been constructed-but, for spinning sounding rockets, three-axis magnetometers contribute no additional information.

*Presented at the Geoscience Electronics Symposium of the Institute of Electrical and Electronics Engineers, April 1969. 


\section{MAGNETOMETER CIRCUIT}

A block diagram of the instrument is shown in Figure 1. As can be observed, this is a standard configuration for a fluxgate magnetometer. The two detectors are of the phase-sensitive type in order to determine the direction of the external field. In the actual instrument, the sensing core performs simultaneously the functions of a sensing element and of a frequency controlling device for the magnetic multivibrator.

A detailed circuit diagram is shown in Figure 2. Q1 and Q2 are the switching transistors for the magnetic multivibrator, which drives the core periodically into saturation at a rate determined by the core characteristics. The second harmonic reference signal is obtained by differentiating

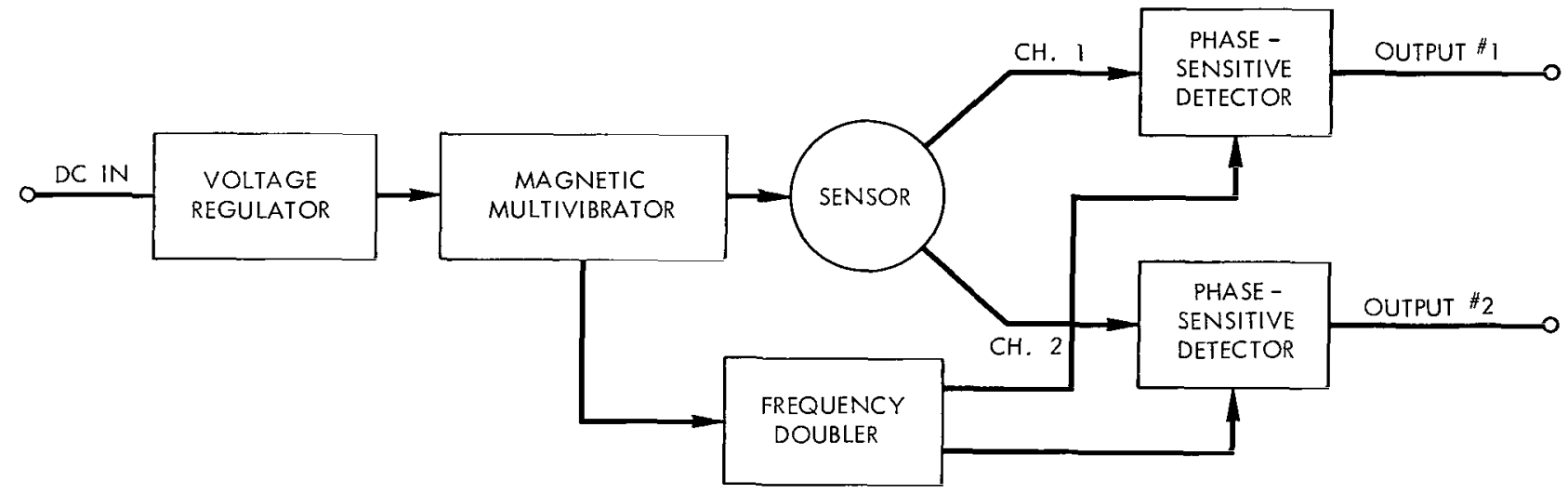

Figure $1-B$ lock diagram of two-axis ring-core magnetometer.

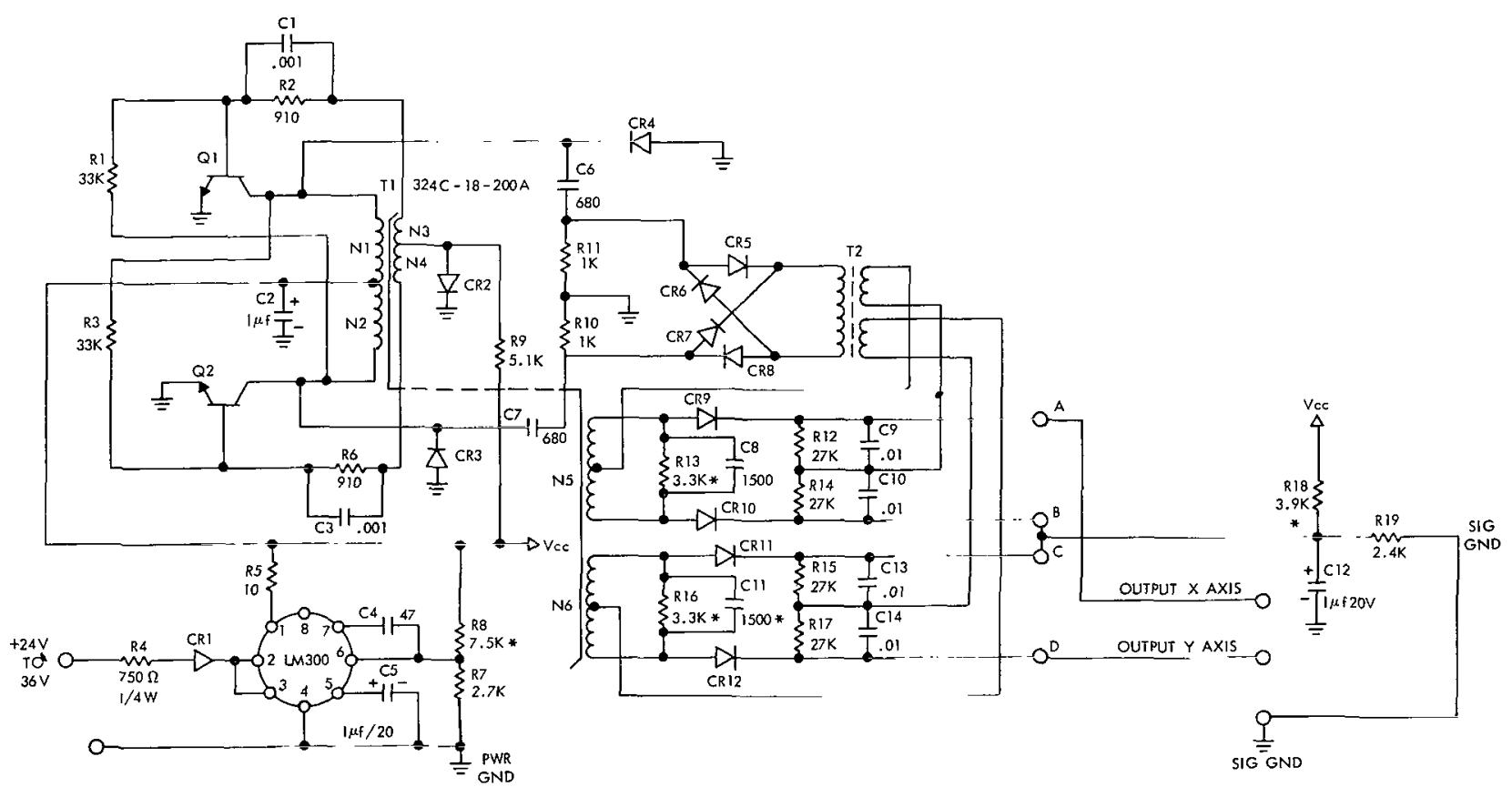

Figure 2-Schematic diagram. 
the square-wave drive voltage and full-wave rectification of the resulting "spikes." T2 is an isolation transformer which, in addition, allows each output to be biased at any desired level, i.e., 2.5 volts for telemetry applications.

The sensitivity of each axis is adjusted by varying the damping resistors across the pickup windings, which are tuned to the second harmonic of the drive frequency. When measuring the earth's magnetic field, this sensitivity is adjusted to 4 volts/oersted, although the intrinsic sensitivity of the instrument manufactured for sounding rocket use is of the order of 60 volts/oersted. This adjustment improves the linearity of the response and maintains the simplicity of the instrument.

As the amplitude of the second harmonic reference is of the same magnitude as the supply voltage, the maximum dynamic range of the instrument is limited by this voltage. Typical values are \pm 10 volts, when no bias is applied to the output. The supply voltage is regulated by means of an integrated-circuit voltage regulator, to accommodate large variations of the input voltage-as are typical of sounding rocket environments. As the operating frequency of the magnetic multivibrator is directly dependent upon its input voltage, it is important to use a regulator with good regulation characteristics and low output impedance. The frequency of operation of the instrument is $100 \mathrm{kHz}$, and intrinsic power consumption is $60 \mathrm{mw}$.

The design of the sensing core is shown in Figure 3. Two orthogonal pickup windings are diametrically wound around the core, and occupy a small portion of the periphery in order to minimize cross-coupling effects and to improve angular response characteristics. The number of turns in each pickup winding is only about 100; thus there is enough room to accommodate each winding around the core in the fashion shown. A plastic winding guide is used to maintain the orthogonal alignment of these windings to within one degree. Typical core size used is $0.5 \mathrm{inch}$ in diameter and 0.125 inch in depth.

\section{ANALYSIS OF OPERATION}

The following assumptions are made in the analysis:

(a) The hysteresis loop is approximated by a piecewise linear function as shown in Figure 4.

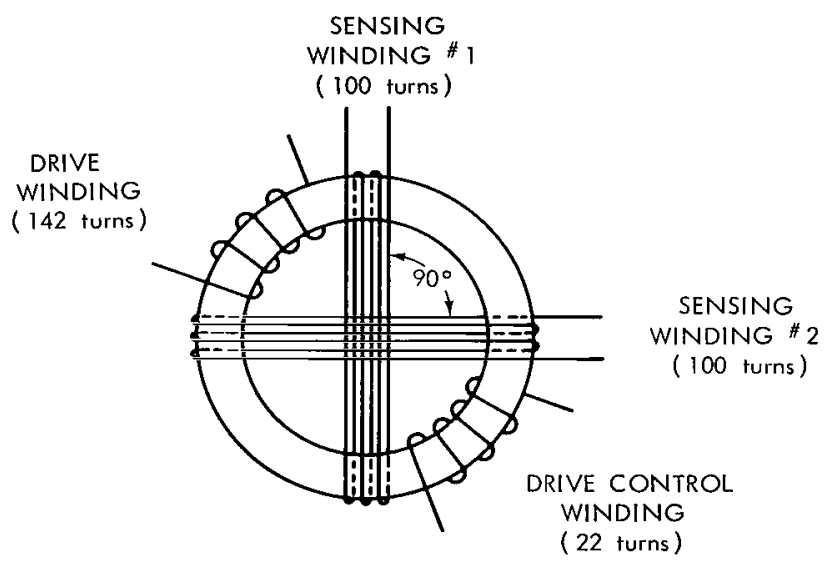

Figure 3-Design of the sensing core.

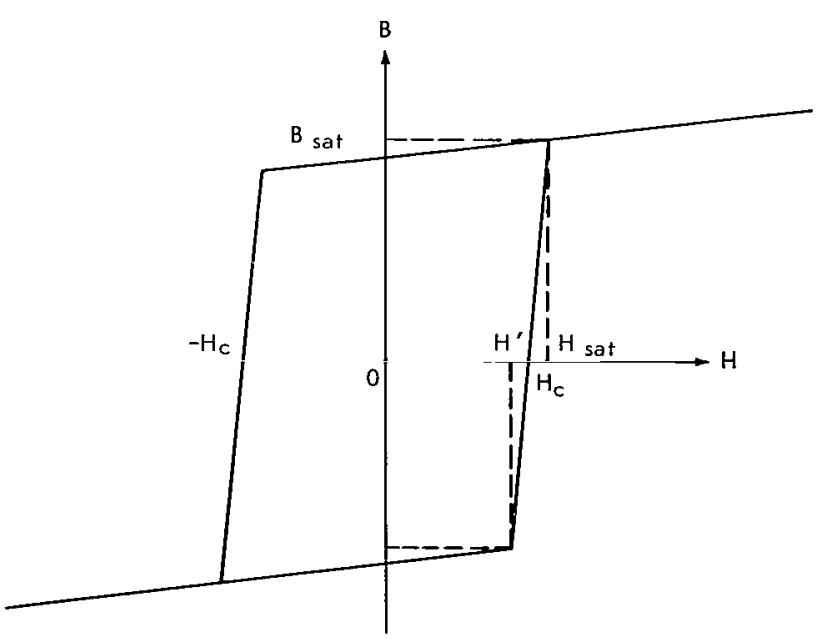

Figure 4-Hysteresis loop. 
(b) The $h_{f e}$ of the transistors is independent of collector current.

(c) The drive waveform is a perfect square wave.

(d) Stray and distributed capacitances are neglected.

Under assumption (c), the flux variation is a linear function of time; therefore, the current waveform is determined by the characteristics of the hysteresis loop. As will be shown later, the approximation of the hysteresis loop by a piecewise linear function is justified by the fact that the areas of the resulting waveforms, and therefore their Fourier coefficients, are dependent only upon the flux-versus-time variation, which is forced to be linear by assumption (c). This is a good first-order approximation to the actual behavior of the circuit. The effect of a real hysteresis loop would be to smooth out sharp corners and spikes in the waveforms shown in Figure 4, but their Fourier coefficients would not be appreciably changed.

With reference to Figures 4 and 5, we can write for the current drive function or excitation:

$$
\begin{aligned}
& 0 \leq \mathrm{t} \leq \mathrm{t}_{2} ; \quad \mathrm{H}(\mathrm{t})=\frac{\mathrm{H}_{\mathrm{max}}+\mathrm{H}^{\prime}}{\mathrm{t}_{2}}-\mathrm{t}-\mathrm{H}_{\max } \\
& \mathrm{t}_{2} \leq \mathrm{t} \leq \mathrm{t}_{4} ; \quad \mathrm{H}(\mathrm{t})=\frac{\left(\mathrm{Hsat}-\mathrm{H}^{\prime}\right)\left(\mathrm{t}-\mathrm{t}_{4}\right)}{\mathrm{t}_{4}-\mathrm{t}_{2}}+\mathrm{Hsat} \\
& \mathrm{t}_{4} \leq \mathrm{t} \leq \mathrm{T} / 2 ; \quad \mathrm{H}(\mathrm{t})=\frac{\left(\mathrm{H}_{\mathrm{max}}-\mathrm{H}_{\mathrm{sat}}\right)}{\mathrm{T} / 2-\mathrm{t}_{4}}(\mathrm{t}-\mathrm{T} / 2)+\mathrm{H}_{\max }
\end{aligned}
$$

where $H^{\prime}$ is given by

$$
H^{\prime}=H_{c}-\frac{B_{s a t}}{\mu_{\Delta}}-2 \mu_{s a t} H_{c}
$$

$$
\begin{aligned}
\mu_{\triangle} & =\text { differential permeability } \\
\mu_{\text {sat }} & =\text { saturation permeability } \\
\mathrm{B} & =\text { flux density. }
\end{aligned}
$$

Using the relation

$$
\frac{\mathrm{d} \phi}{\mathrm{dt}}=\mathrm{A} \frac{\mathrm{dB}}{\mathrm{dt}}=\mu \mathrm{A} \frac{\mathrm{dH}}{\mathrm{dt}}=\frac{4 \phi_{\max }}{\mathrm{T}},
$$




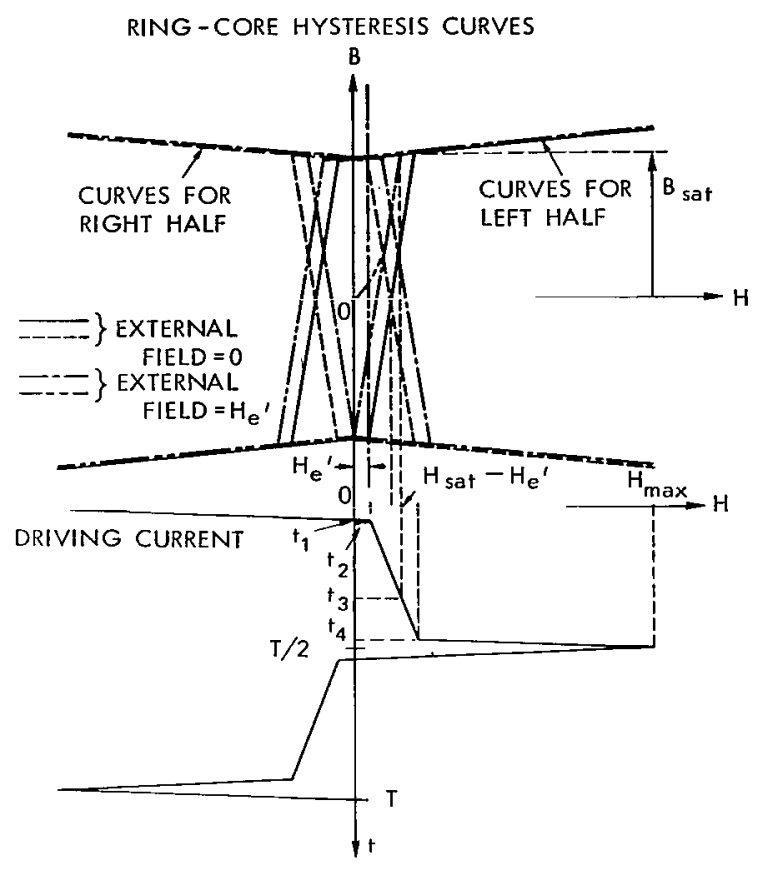

VOLTAGE AND FLUX VS TIME

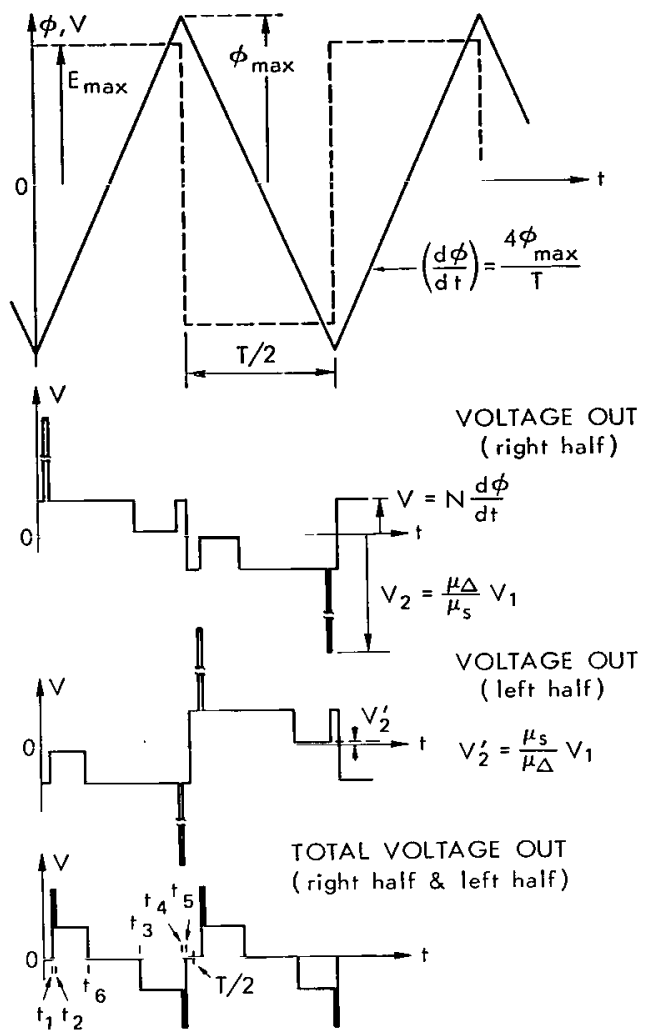

Figure 5-Hysteresis curves and waveforms.

we can compute

$$
\mathrm{t}_{2}=\frac{\mathrm{T}_{\mu_{\text {sat }}}\left(\mathrm{H}_{\max }+\mathrm{H}^{\prime}\right)}{4 \mathrm{~B}_{\max }}
$$

where

$$
\mathrm{B}_{\text {max }}=\mu_{\Delta}\left(H_{s a t}-H_{c}\right)+\mu_{s a t}\left(H_{\text {max }}-H_{\text {sat }}\right)
$$

and

$$
t_{4}=\frac{T_{\mu \Delta}\left(H_{\text {sat }}-H^{\prime}\right)}{4 B_{\max }}+t_{2}
$$




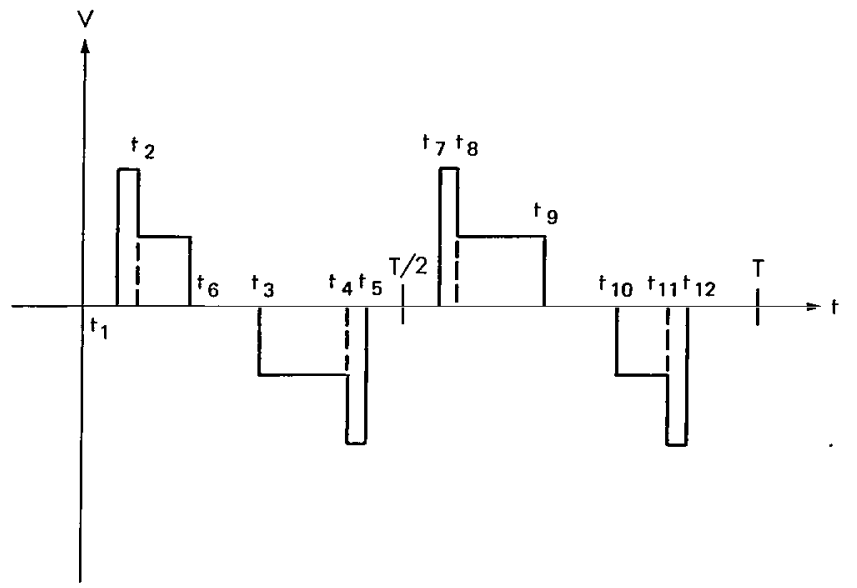

Figure 6-The resulting waveform.

The presence of an external magnetic field causes, in each half of the core, the appearance of an additional excitation $\mathrm{H}_{e}$ which is related to the external field by means of the demagnetizing factor discussed later. We have then, from Figure 5, for the right half of the core,

$$
\begin{aligned}
& t_{1}=\frac{\left(H^{\prime}-H_{e}+H_{\max }\right) t_{2}}{H_{\max }+H^{\prime}}, \\
& t_{3}=\frac{t_{4}-H_{e}\left(t_{4}-t_{2}\right),}{H_{\text {sat }}-H^{\prime}},
\end{aligned}
$$

and analogously for the left half,

$$
\begin{aligned}
& t_{5}=\mathrm{T} / 2+\frac{\left(\mathrm{H}_{\mathrm{sat}}+\mathrm{H}_{\mathrm{e}}-\mathrm{H}_{\mathrm{max}}\right)\left(\mathrm{T} / 2-\mathrm{t}_{4}\right)}{\mathrm{H}_{\text {max }}-\mathrm{H}_{\mathrm{sat}}}, \\
& \mathrm{t}_{6}=\mathrm{t}_{4}+\frac{\left(\mathrm{H}^{\prime}+\mathrm{H}_{\mathrm{e}}-\mathrm{H}_{\mathrm{sat}}\right)\left(\mathrm{t}_{4}-\mathrm{t}_{2}\right) .}{\mathrm{H}_{\text {sat }}-\mathrm{H}^{\prime}},
\end{aligned}
$$

As the resulting waveform (Figure 6 ) is symmetrical about $\mathrm{T} / 2$, we can also write

$$
\begin{aligned}
& t_{7}=T-t_{5} . \\
& t_{8}=T-t_{4} . \\
& t_{9}=T-t_{3} . \\
& t_{10}=T-t_{6} . \\
& t_{11}=T-t_{2} . \\
& t_{12}=T-t_{1} .
\end{aligned}
$$

The amplitudes of the resulting voltages in Figure 5 are given by

$$
V_{1}^{\prime}=\frac{4 \mathrm{NAB}_{\max }}{\mathrm{T}}\left(1-\frac{\mu_{\text {sat }}}{\mu_{\Delta}}\right) \times 10^{-8}
$$


and

$$
\mathrm{v}_{2}^{\prime}=\frac{\mu_{\Delta}}{\mu_{\mathrm{sat}}} \mathrm{v}_{1}^{\prime}
$$

where

$B_{\max }$ is given by Equation 7, and

$\mathrm{N}=$ number of turns in the pickup winding,

$A=$ cross - sectional area of the magnetic core.

The differential voltage output can now be decomposed into its Fourier components in order to determine the amplitude of the second harmonic signal as a function of the external field. The results of this analysis can be summarized as follows:

$$
f(t)=\sum_{n=1}^{\infty}\left(A_{n} \cos n w t+B_{n} \sin n w t\right)
$$

where

$$
A_{n}=\frac{2}{T} \int_{0}^{T} f(t) \cos n w t d t=0 \text { (odd function) }
$$

The $B_{n}$ coefficient is then given by

$$
\begin{aligned}
B_{n}=\frac{2}{T} \int_{0}^{T} f(t) \sin n w t d t= & \frac{V_{2}^{\prime}}{\pi n}\left(\cos \frac{2 \pi n t_{1}}{T}-\cos \frac{2 \pi n t_{2}}{T}\right) \\
& +\frac{V_{1}^{\prime}}{\pi n}\left(\cos \frac{2 \pi n t_{2}}{T}-\cos \frac{2 \pi n t_{6}}{T}\right) \\
& -\frac{V_{1}^{\prime}}{\pi n}\left(\cos \frac{2 \pi n t_{3}}{T}-\cos \frac{2 \pi n t_{4}}{T}\right)-\frac{V_{2}^{\prime}}{\pi n}\left(\cos \frac{2 \pi n t_{4}}{T}-\cos \frac{2 \pi n t_{5}}{T}\right) \\
& +\frac{V_{2}^{\prime}}{\pi n}\left(\cos \frac{2 \pi n t_{7}}{T}-\cos \frac{2 \pi n t_{8}}{T}\right)+\frac{V_{1}^{\prime}}{\pi n}\left(\cos \frac{2 \pi n t_{8}}{T}-\cos \frac{2 \pi n t_{9}}{T}\right) \\
& -\frac{V_{1}^{\prime}}{\pi n}\left(\cos \frac{2 \pi n t_{10}}{T}-\cos \frac{2 \pi n t_{11}}{T}\right)-\frac{V_{2}^{\prime}}{\pi n}\left(\cos \frac{2 \pi n t_{11}}{T}-\cos \frac{2 \pi n t_{12}}{T}\right) .
\end{aligned}
$$


For $\mathrm{n}=2$ we obtain the amplitude of the second harmonic signal,

$$
\mathrm{B}_{2}=\frac{\mathrm{V}_{2}^{\prime}}{2 \pi}\left(\cos \frac{4 \pi \mathrm{t}_{1}}{\mathrm{~T}}-\cos \frac{4 \pi \mathrm{t}_{2}}{\mathrm{~T}}\right)+\cdots .
$$

Because of the complexity of the dependence of the coefficient $B_{2}$ on the external field, a closedform result is meaningless; ther efore, the equations described were programmed in a digital computer for different values and combinations of the parameters involved. The results of these computations are presented later on in this paper.

\section{THE DEMAGNETIZING FACTOR}

In order to determine the functional relationship between the external field and the excitation appearing in each half of the core, $\mathrm{H}_{\mathrm{e}}$ the so-called "demagnetizing factor," must be included in the analysis.

If we assume the core to be an infinitely long cylinder and solve the magnetostatic potential problem described by

$$
\nabla^{2} \Phi_{\mathrm{m}}=0 ; \quad \mathrm{H}=-\nabla \Phi_{\mathrm{m}}
$$

subject to appropriate boundary conditions, the results obtained are not satisfactory, as the predicted excitation for a given external field is far too small and does not agree with laboratory measurements.

Following the approach taken by Gordon (Reference 3), based on Bozorth's (References 4 and 5) work with ellipsoids and long rods, the relationship between the input signal $\mathrm{H}$ and the resulting excitation $\mathrm{H}_{\mathrm{e}}$ can be expressed as

$$
\mathrm{H}_{\mathbf{e}}=\mathrm{H}-\mathrm{H}_{\mathrm{d}}
$$

where $H_{d}$ is the self-demagnetizing field. Now

$$
\mathrm{H}_{\mathrm{d}}=\mathrm{K}\left(\mathrm{B}-\mu^{\prime} \mathrm{H}\right)
$$

where $\mu^{\prime}$ is the permeability of the surrounding medium (air) and $\mathrm{K}$ is the demagnetizing factor. If

$$
\mathrm{B}=\mu \mathrm{H} \gg \mu^{\prime} \mathrm{H}
$$


(since $\mu>1,000 \mu^{\prime}$ ), then

$$
\mathrm{H}_{\mathrm{d}} \cong \mathrm{KB}=\mathrm{K} \mu \mathrm{H}_{\mathrm{e}}
$$

where $\mu$ is the permeability of the core material. For long rods, the demagnetizing factor $\mathrm{K}$ can be approximated as

$$
\mathrm{K} \cong(\mathrm{L} / \mathrm{d})^{-1.72} \quad(\text { for } \mu=\infty)
$$

where $\mathrm{L} / \mathrm{d}$ is the ratio of the length of the rod to its diameter. We then can write

$$
\frac{\mathrm{H}_{\mathrm{e}}}{\mathrm{H}}=1+\mu(\mathrm{L} / \mathrm{d})^{-1.72} .
$$

In the case of a ring-core magnetometer, L corresponds to the length around one half of the circumference of the core, and $\mathrm{d}$ to the diameter of a rod with cross-section area equivalent to that of the magnetic core. This assumption has been used in the analysis. If the external field is small, i.e., $10^{-4}$ oersteds, the permeability to be used in Equation 24 is the initial permeability of the material $\mu_{0}$. However, for larger fields this is no longer true. In this case we have approximated the variation of the permeability with the applied field by means of an exponential function, i.e.,

$$
\mu \quad-\mu_{0} \mathrm{~K}_{0}{ }^{\mathrm{H}}{ }^{\mathrm{e}}
$$

in other words, " $\cdots, \wedge$ as $\mathrm{H}_{\mathrm{e}}, \mathrm{H}_{\mathrm{c}}$; this behavior is used to determine the value of the constant $\mathrm{K}_{0}$.

As Equation 24 is now a transcendental equation, the corresponding internal field for each value of the assumed external field was obtained by performing an iterative calculation of Equations 24 and 25 to the desired degree of accuracy, typically 0.1 percent.

\section{COMPARISON OF PREDICTED AND OBSERVED PERFORMANCE}

Figure 7 shows the predicted and actual responses of the two channels in a flight magnetometer with a 4-79 Mo-Permalloy core, $(\mathrm{L} / \mathrm{d}=46)$. No adjustment constants have been incorporated in the model to approximate actual results. The variation of the permeability with the internal field is assumed to be exponential, as described earlier. Material properties were obtained from Reference 6 . 


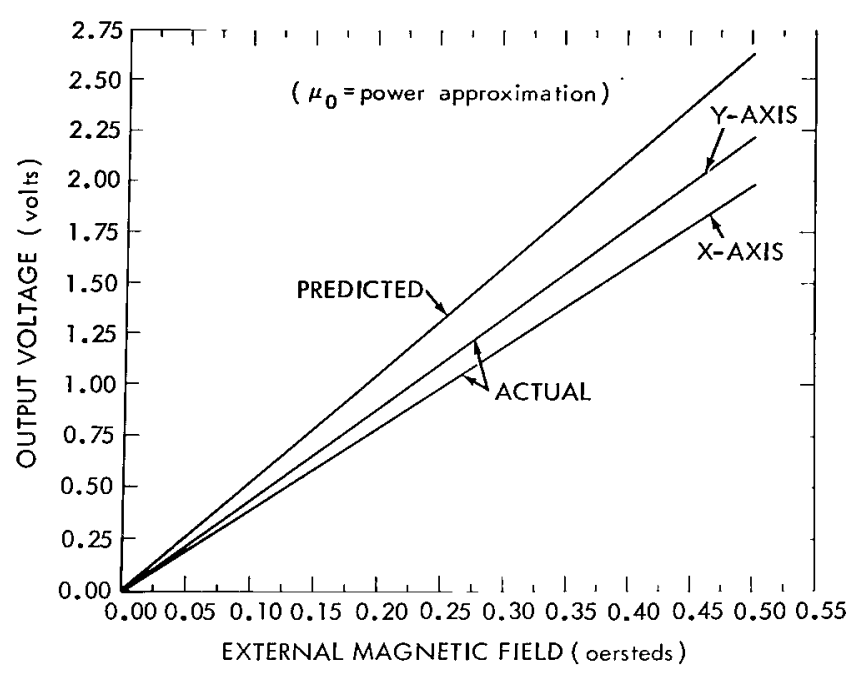

Figure 7-Output voltage vs external field (4-79 Mo-Permalloy).

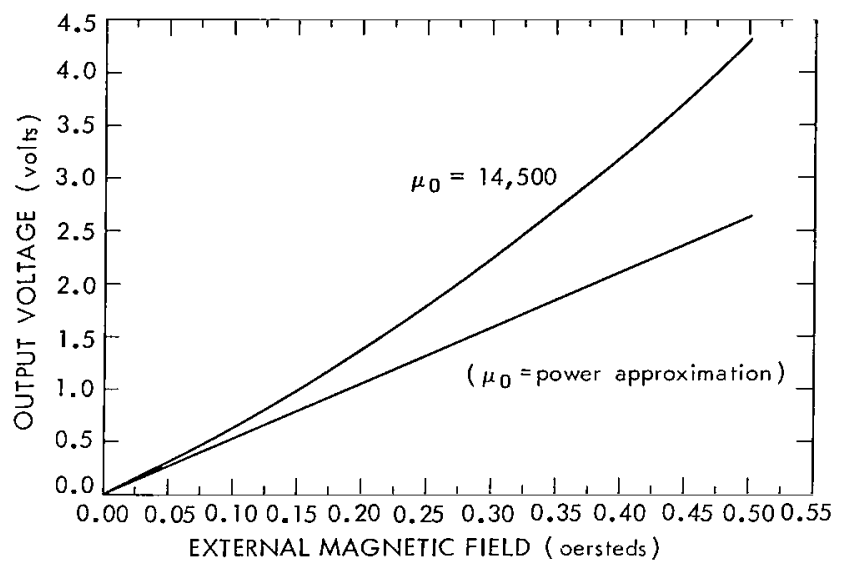

Figure 8-Output voltage vs magnetic field (4-79 MoPermalloy-comparison of constant and exponential $\mu_{0}$ approximations).
Figure 8 shows a comparison of the results obtained assuming constant and exponentially varying functions for the permeability. As the attenuation factor,

$$
A_{t}=\frac{H_{e}}{H}=\frac{1}{1+\mu_{0}(1 / d)^{-1.72}}
$$

is strongly dependent upon the permeability of the material, it is advantageous to use lowinitial-permeability core materials. In the case of 50-50 Ni-Fe (Deltamax), $\mu_{0}=560$; and, for the same $\mathrm{L} / \mathrm{d}$ ratio, the attenuation factor is about 5 percent of the corresponding value for 4-79 Mo-Permalloy. In addition, the maximum flux density for this material is about twice the value of that for 4-79 Mo-Permalloy -a property which, for a constant operating frequency, would allow the use of a core with one-half of the cross-section area. Hence a higher $\mathrm{L} / \mathrm{d}$ ratio would be obtained, thus decreasing even further the attenuation factor. However, the area of the hysteresis curve for 50-50 Ni-Fe is about 10 times the corresponding area for 4-79 Mo-Permalloy; therefore, drive-power requirements are increased by an order of magnitude.

The predicted response for a $50-50 \mathrm{Ni}-\mathrm{Fe}$ ring-core magnetometer is presented in Figure 9, and compared to that of a 4-79 MoPermalloy instrument with same $\mathrm{L} / \mathrm{d}$ ratio. The exponential approximation function for the permeability was used in both cases.

The nature of the computer program used to analyze the equations describing the operation of the magnetometer allows any desired parameter to be incrementally varied, and the resulting output voltage to be displayed as a family of curves (Figure 10) for different values of the external field; in this case $.1, .2, .3, .4$, and .5 oersteds. All of these curves describe results obtained for 4-79 Mo-Permalloy core material with $\mu_{0}$ represented by the exponential approximation. Curves for $50-50 \mathrm{Ni}-\mathrm{Fe}$ are not shown, as they are similar and experimental verification has not been completed. 


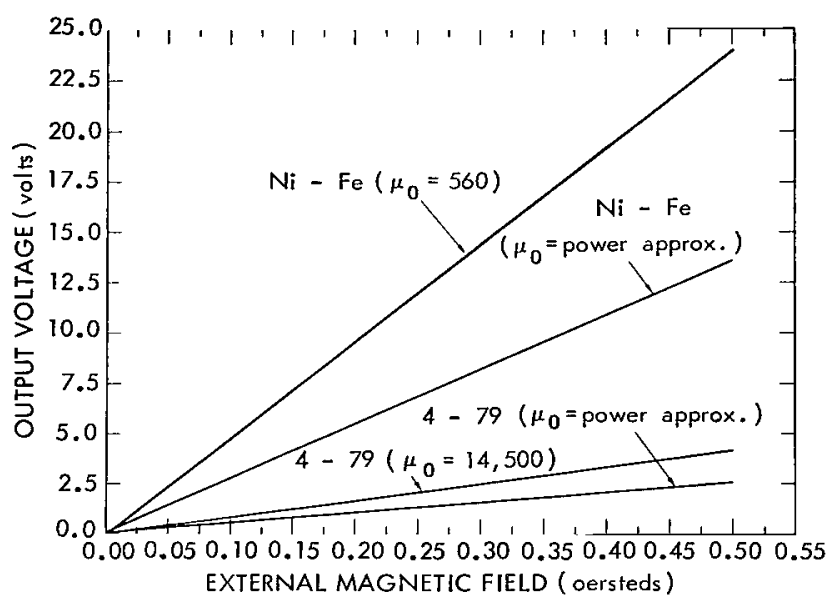

Figure 9-Output voltage vs external field (4-79 Mo-Permalloy and $\mathrm{Ni}-\mathrm{Fe}$ core materials).

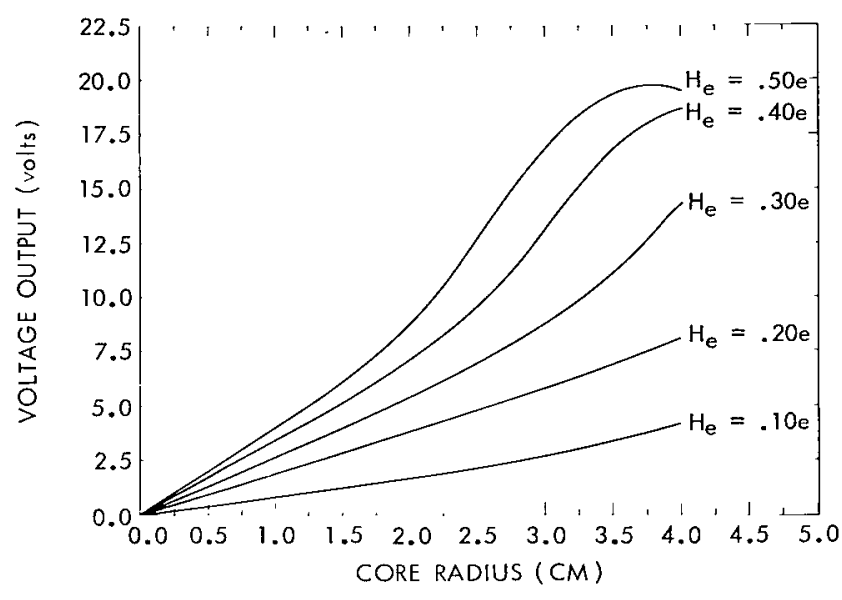

Figure $11-V o l t a g e$ output vs core radius (50-50 Ni-Fe Permalloy).

Figure 10 shows the output variation as a function of the applied input voltage. The sharp increase in sensitivity is due, among other factors, to the increase in operating frequency characteristic of the magnetic multivibrator.

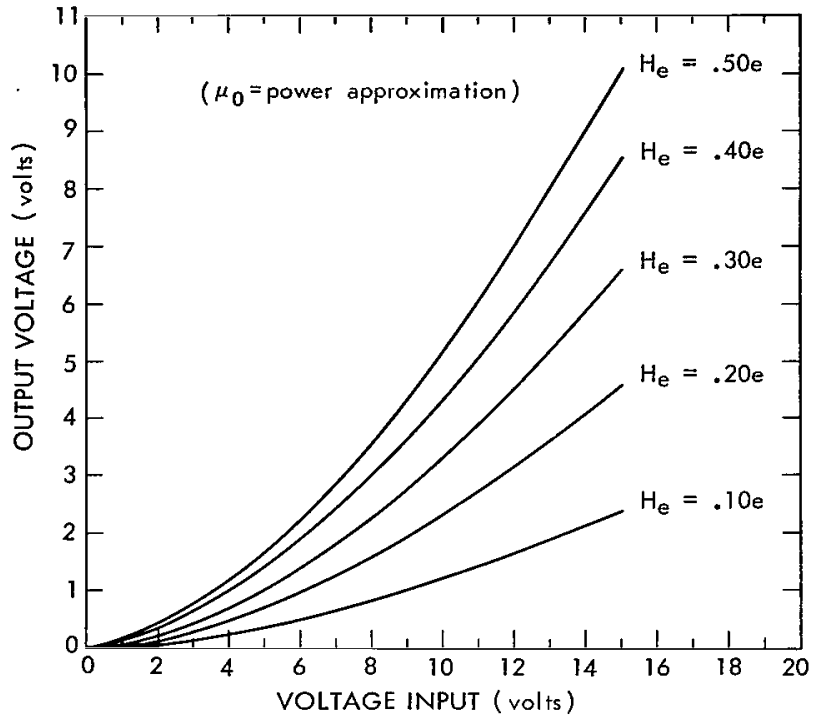

Figure 10-Voltage output vs input voltage (frequency) (4-79 Mo-Permalloy).

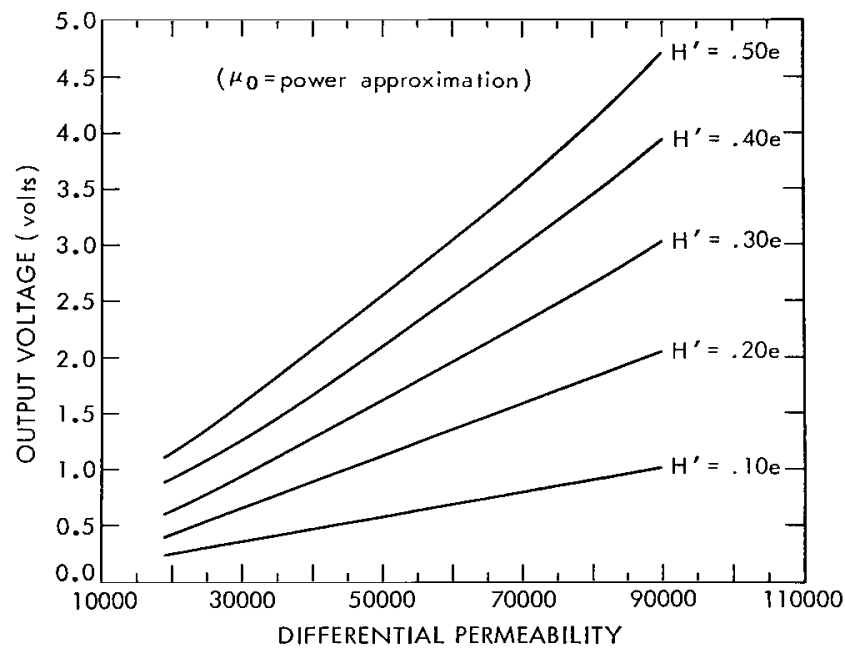

Figure 12-Output voltage vs differential permeability (4-79 Mo-Permalloy).

The output variation as a function of the core radius is shown in Figure 11. As this radius is increased, the $\mathrm{L} / \mathrm{d}$ ratio becomes larger, thus decreasing the attenuation factor. Figures 12,13 , and 14 show the effects of varying material-dependent parameters. The customary definitions are used, except that these parameters are defined in terms of the assumed piecewise linear $\mathrm{B}-\mathrm{H}$ curve for the theoretical model. 


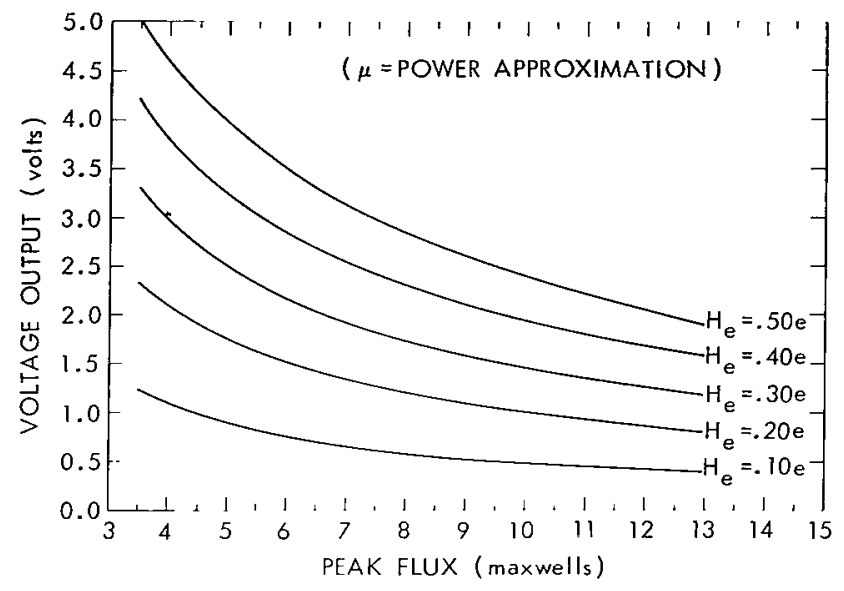

Figure 13-Output voltage vs peak flux (4-79 Mo-Permalloy).

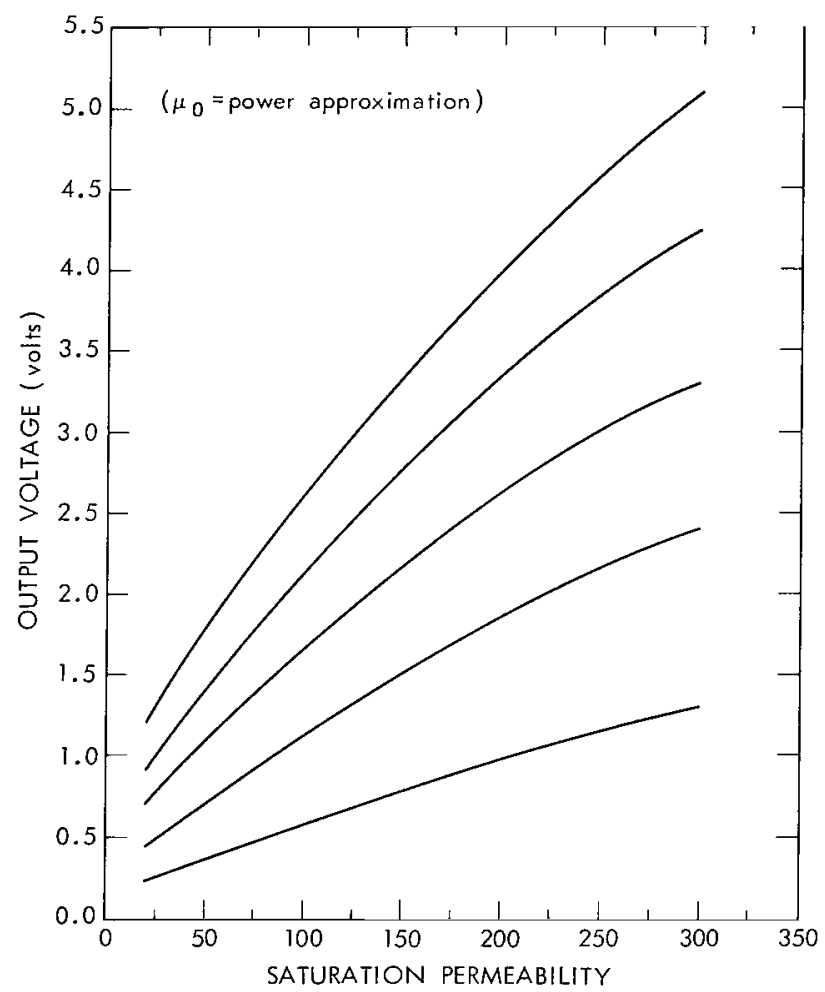

Figure 14-Voltage output vs saturation permeability (4-79 Mo-Permalloy).

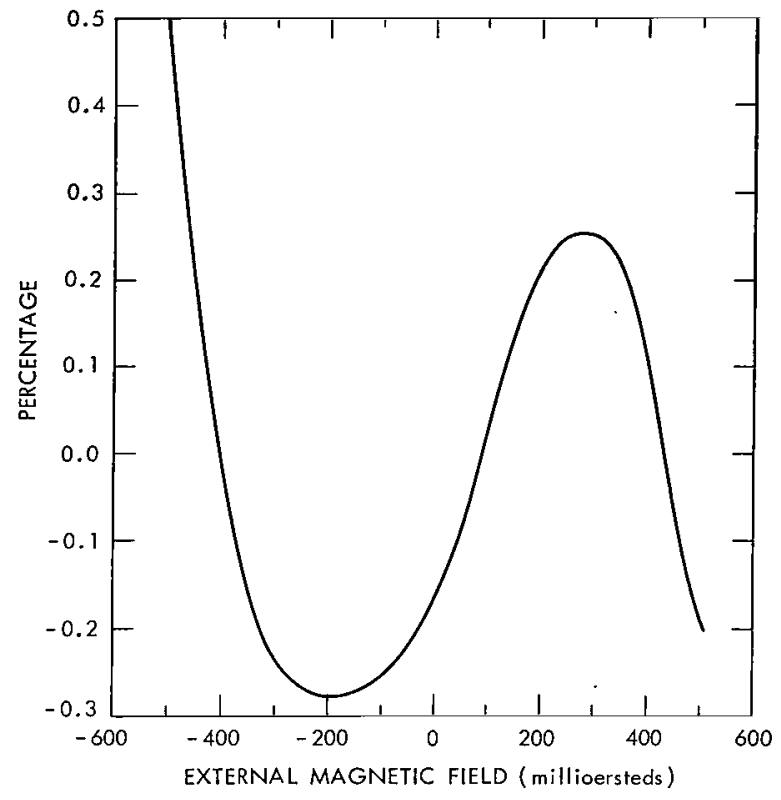

Figure 15-Percentage deviation from

linear fit vs external field ( $X$-axis).

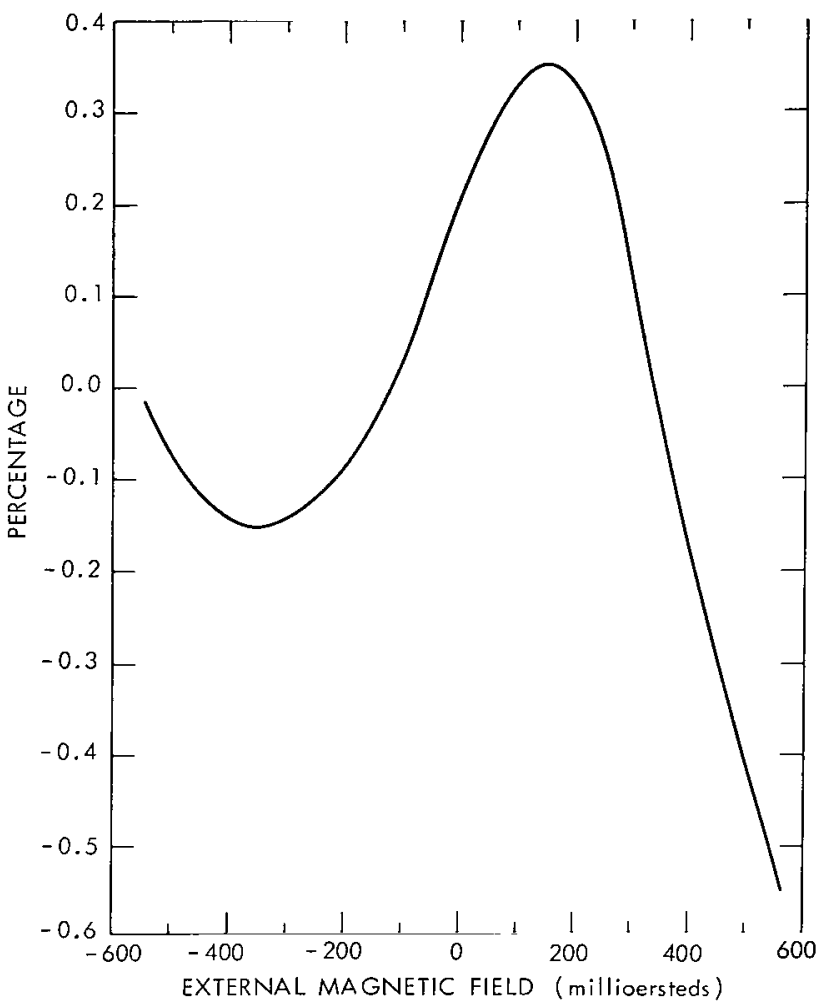

Figure 16-Percentage deviation from linear fit $v s$ external field $(Y$-axis). 


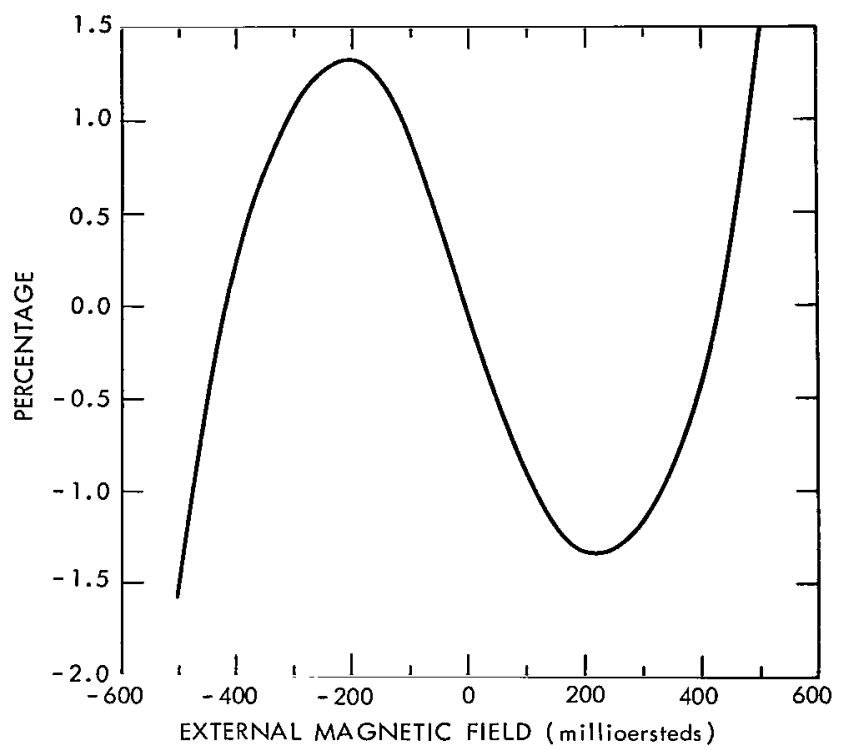

Figure 17-Percentage deviation from linear fit vs external field (mathematical model).

\section{ERROR ANALYSIS}

For the flight magnetometer mentioned earlier, the percentage deviation of the output voltage from a least-squares straight-line fit is shown in Figures 15 and 16. The S-shaped curve is typical of fluxgate magnetometers, and is the result of the gradual decrease in sensitivity as the external field is increased in magnitude. The increase of $k_{0}$ as a function of the internal field and the nonlinearities of the actual B-H curve are probably the dominant causes of this decrease.

Figure 17 shows a plot of the linearity error obtained from the theoretical response predicted by the model. As can be observed, the model satisfactorily approximates the actual error curve. In aspect sensing applications, it is important to determine how closely the angular response of the magnetometer follows a $\cos \theta$ type curve. Figures 18, 19, and 20 show the percentage deviation from an ideal $\cos \theta$ response curve as a function of the orientation angle of the instrument with respect to the external field. In Figures 18 and 19, the external field is rotated about an axis perpendicular to the plane of the core, a procedure which allows both outputs to be read out simultaneously; i.e., $\mathrm{K} \cos \theta$ and $\mathrm{K} \sin \theta$ response. In Figure 20, the external field is perpendicular to, and rotated about, the $\mathrm{X}$ - axis.

For this analysis, the linearity error has been removed to a first-order approximation by a piecewise linear calibration process. The sinusoidal nature of the resulting curves is probably 


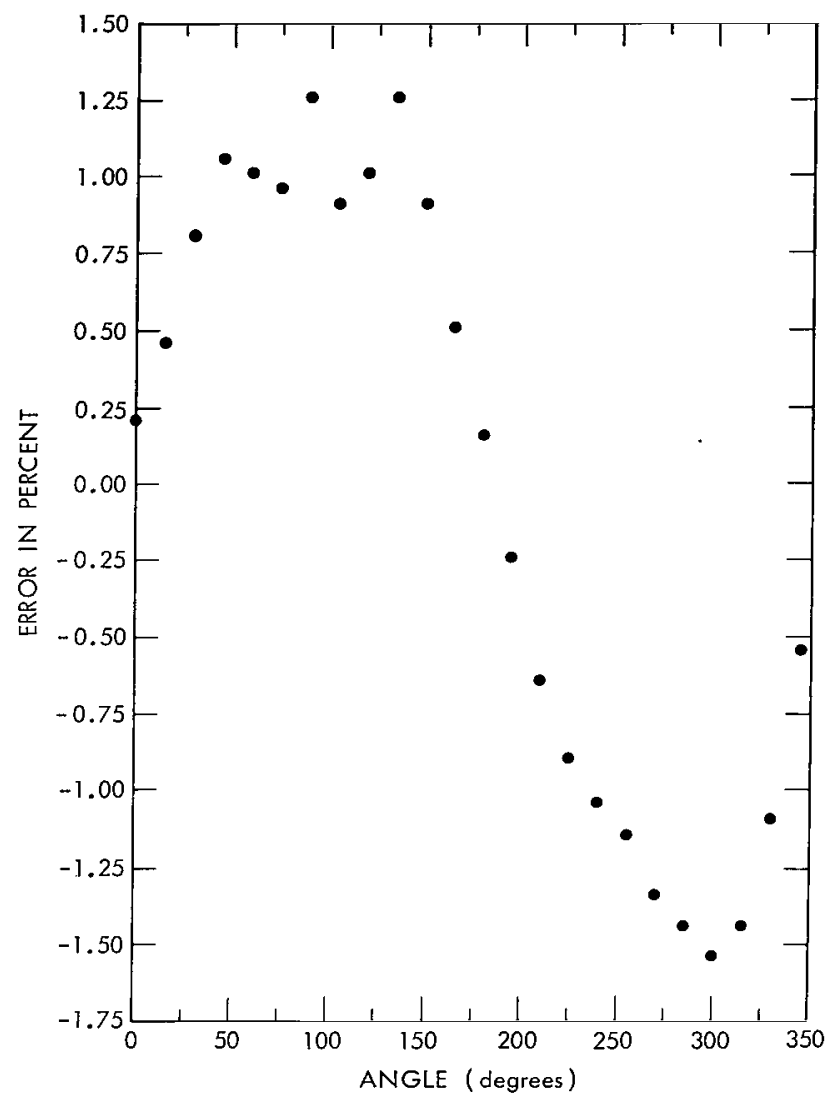

Figure 19-Percentage deviation from cosine response vs angle ( $Y$-axis output, rotation in plane of core).

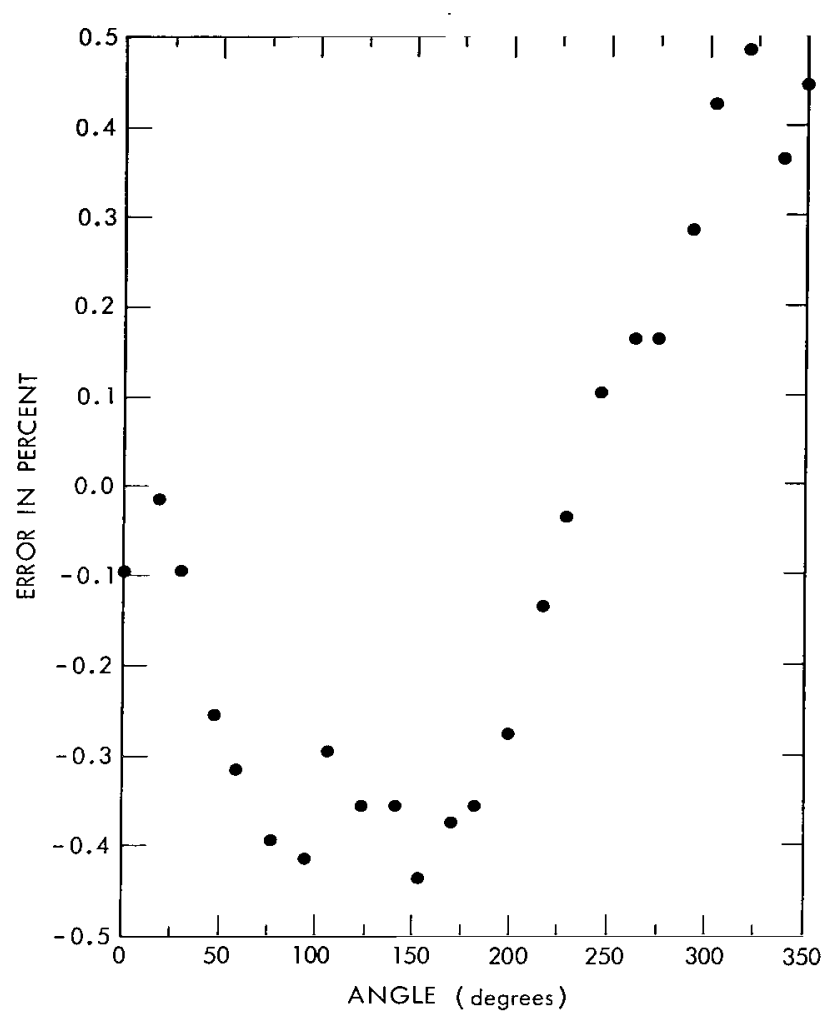

Figure 20-Percentage deviation from cosine response vs angle ( $X$-axis output, rotation about $Y$-axis).

caused by a constant angular misalignment with respect to the external field. In practice, the above-described errors are largely reduced during actual data reduction by performing a direct voltage-to-angle conversion and using the calibration curves to correct the results.

\section{CONCLUSIONS}

An accurate two-axis magnetometer of extreme simplicity can be constructed utilizing a single ring-core sensor, and sensitivities of the order of $1 \mathrm{mv} / \gamma$ can be obtained. When the ring core performs the dual functions of frequency controlling device and sensor element, a linear mathematical model can be formulated which accurately predicts observed performance. This model allows several parameters to be incrementally varied, and their effects on sensitivity and linearity of the magnetometer analyzed.

Linearity and angular response characteristics of the actual instrument are very good and follow smooth, predictable patterns. This fact allows the use of correction factors during the data reduction process which improve the overall attainable accuracy of the instrument. 


\section{ACKNOWLEDGMENTS}

It is a pleasure to thank J. Hudgins, J. Scarzello, R. Flynn, and G. Bell for their great assistance enabling us to carry out this project.

Goddard Space Flight Center

National Aeronautics and Space Aciministration

Greenbelt, Maryland, June 18, 1969

879-70-01-03-51

\section{REFERENCES}

1. Geyger, W. A., "Non-Linear Magnetic Control Devices," New York: McGraw-Hill Book Company, 1964, Chs. 13 and 14.

2. Geyger, W. A., "The Ring Core Magnetometer - A New Type of Second Harmonic Flux Gate Magnetometer," AIEE Trans. 81, 1965, pp. 65-73.

3. Gordon, D. I., Lundsten, R. H., and Chiarodo, R. A., "Factors Affecting the Sensitivity of Gamma Level Ring Core Magnetometers," IEEE Trans. on Magnetics, Vol. 1, No. 4, 1965, pp. 330-337.

4. Bozorth, Richard M., "Ferromagnetism," Princeton, N. J.: D. Van Nostrand Co., Inc., 1951.

5. Bozorth, R. M., and Chapin, D. M., "Demagnetizing Factors of Rods," Journal of Applied Physics 13:320-326, May 1942.

6. "Properties of Deltamax, 4-79 Mo-Permalloy, Supermalloy," Bulletin TC-101-A, Arnold Engineering Co., Marengo, Ill.

\section{BIBLIOGRAPHY}

Falkoff, A. D., and Iverson, K. E., "APL/360: User's Manual," IBM Corporation, T. J. Watson Research Center, Poughkeepsie, N. Y., 1968.

Jackson, J. D., "Classical Electrodynamics," New York: John Wiley \& Sons, 1967, Ch. 5.

Marshall, Stanley V., "An Analysis of the Ring-Core Flux-Gate Magnetometer," Univ. of Missouri, Columbia, Missouri.

Pipes, L. A., "Applied Mathematics for Engineers and Physicists," New York: McGraw-Hill Book Company, 1968. 
Appendix A

\section{Technical Description of the Miniature Fluxgate Magnetometer, Type FMF}

The MFM is a miniature two-axis magnetometer designed at Goddard Space Flight Center for rocket aspect sensing. It simultaneously measures two perpendicular components of an external magnetic field. Sufficient data, therefore, are obtained to determine magnetic aspect as well as the total field for spinning rockets. These parameters can be determined twice as often as the spin rate of the rocket.

The MFM operates on the fluxgate principle. A toroidal sensor is driven into saturation at $120 \mathrm{kHz}$. The sensor therefore radiates, but because of the toroidal geometry the resulting RFI is very low. When payloads are extremely sensitive to RFI, the MFM can be covered with conducting paint. This reduces the RFI to extremely low levels.

The MFM is biased at $+2.5 \mathrm{v}$ and has an output which swings from 0 to $5 \mathrm{v}$ in an external field of \pm 600 millioersteds ( $\pm 60 \mathrm{~K}$ gammas), or approximately \pm the earth's field. Separate signal and power grounds are provided. The output should be loaded with $100 \mathrm{~K}$ ohms to obtain uniformity of calibration curves.

The MFM may be secured directly to a nonmagnetic shelf with nonmagnetic hardware. Care must be taken to keep magnetic components away from the magnetometer (or vice versa). As the effect of other devices on the magnetometer falls off as $1 /(\text { dist })^{3}$, careful placement is essential. Stray magnetic fields can degrade the accuracy of or saturate the magnetometer with the result that little or no data will be obtained, if the above precautions are not taken. Since angles are being measured, the sensor does not have to be on the roll axis; however, the angular relationships of the magnetometer with some reference point and with the solar sensor must be recorded.

If magnetic aspect or rocket attitude is desired, a magnetometer calibration in the payload is an absolute necessity if accuracy is to be maintained. This requires about one-half day at the GSFC Magnetic Test Facility and should be one of the last things done before flight. The Test Facility should be reserved in advance.

If only roll data are desired, the in-payload calibration may be omitted; but experience has shown that frequently a postflight decision is made to attempt to reconstruct rocket attitude with an uncalibrated magnetometer. This process is always difficult and sometimes impossible. 


\section{MFM Specifications}

(tentative)

Input Voltage: $24 \mathrm{v} d \mathrm{dc}$ to $45 \mathrm{v}$ dc (internal over-voltage protection)

Dimensions: $2-3 / 4^{\prime \prime} \times 1 \frac{1}{4}^{\prime \prime} \times 1-1 / 8^{\prime \prime}$

Input Current: 16 milliamperes

Range of Field: $0 \pm 600$ millioersteds ( $\pm 60 \mathrm{~K}$ gammas)

Sensitivity: $2.5 \mathrm{v} \pm 100 \mathrm{mv}$ per 600 millioersteds

Stability of Sensitivity: $\pm 3 \%$

DC Output for Zero Field: $2.5 \mathrm{v} \pm 50 \mathrm{mv}$

Operating Temperature Range: $0^{\circ} \mathrm{C}$ to $60^{\circ} \mathrm{C}$

Linearity: $\pm 1.5 \%$

Frequency Response: Flat to $500 \mathrm{~Hz}$

Output Impedance: $20 \mathrm{~K}$ ohms

Output Load (for standard calibration): $100 \mathrm{~K}$

Weight: 2 ounces
Connector Pins:
DEM-9-P 1) spare,
2) +28 ,
3) signal ground,
4) power ground, 5) roll axis output,
6) pitch axis output, 7), 8), and 9) spares.

Note: Signal and power ground should be externally tied together.

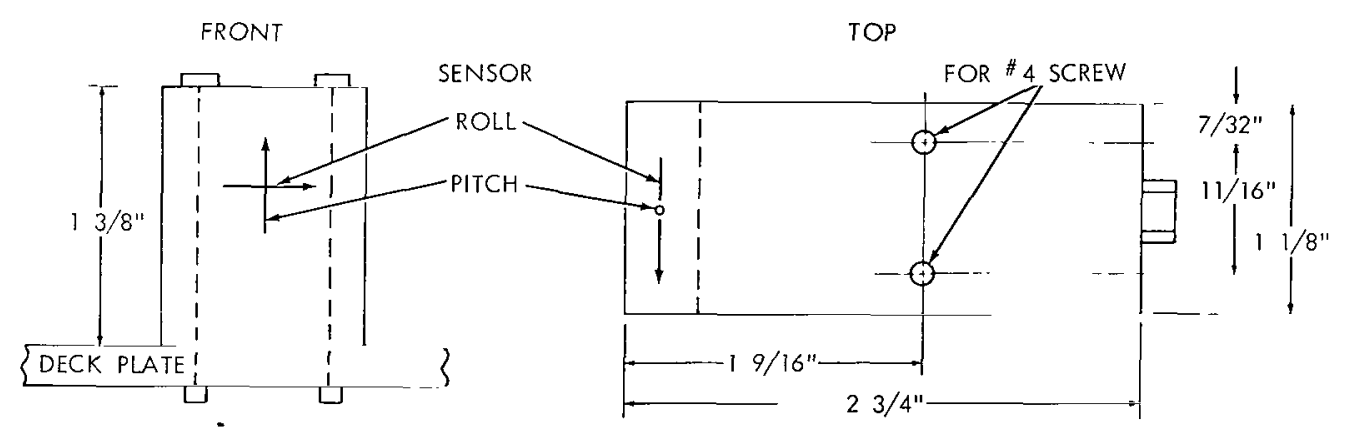


Appendix B

\section{Computer Programs Used in the Analysis}

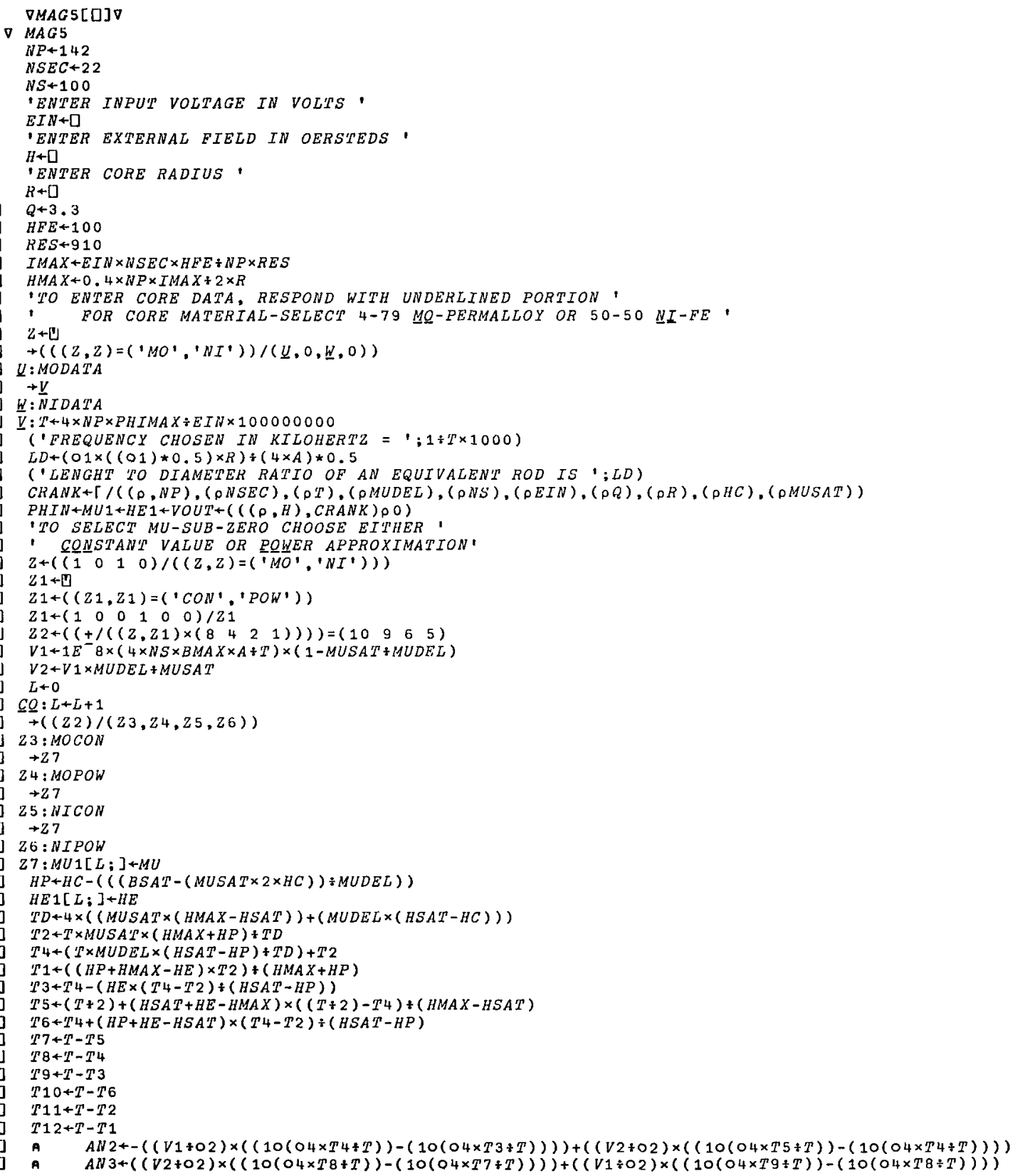


[65] A $A N 4+-((V 1 \div 02) \times((10(04 \times T 11 \div T))-(10(04 \times T 10 \div T))))+((V 2 \div 02) \times((10(04 \times T 12 \div T))-(10(04 \times T 11 \div T))))$

$[66] \quad B N 1+((V 2 \div 02) \times((20(04 \times T 1 \div T))-(20(04 \times T 2 \div T))))+((V 1 \div 02) \times((20(04 \times T 2 \div T))-(20(04 \times T 6 \div T))))$

[67] $B N 2 \div-((V 1 \div 02) \times((20(04 \times T 3 \div T))-(20(04 \times T 4 \div T))))+((V 2 \div 02) \times((20(04 \times T 4 \div T))-(20(04 \times T 5 \div T))))$

[68] $B W 3+((V 2 \div 02) \times((20(04 \times T 7 \div T))-(20(04 \times T 8 \div T))))+((V 1 \div 02) \times((20(04 \times T 8 \div T))-(20(04 \times T 9 \div T))))$

[69] $B N 4+-((V 1 \div 02) \times((20(04 \times T 10 \div T))-(20(04 \times T 11+T))))+((V 2 \div 02) \times((20(04 \times T 11 \div T))-(20(04 \times T 12 \div T))))$

$[70] \rightarrow((T 6)<(T \div 2)) / C O 1$

[71] TOTAL PERIOD EXCEEDED'

$[72] \rightarrow \underline{C} \underline{O} 2$

[73] $\quad$ COI:TP+T:2

$[74]$ A $A N 1+((V 2 \div 02) \times((10(04 \times T 2 \div T))-(10(04 \times T 1 \div T))))+((V 1 \div 02) \times((10(04 \times T 6 \div T))-(10(04 \times T 2 \div T))))$

$[75]$ ค $A N T+A N 1+A N 2+A N 3+A N 4$

[76] $B N T+B N 1+B N 2+B N 3+B N 4$

$[77] \quad C N+B N T$

$[78]$

$[78]$

$[79]$

$[80]$

$[81]$

$[8, j]$

P PHIN[L; ]+C $-30(B N T \div A N T))+01 \times(((A N T \leq 0) \wedge(B N T \geq 0))+((A N T \leq 0) \wedge(B N T \leq 0)))$

$\rightarrow(L<(\rho ; H))+Q \times C N$

CO2: ('OUTPU'T VOLTAGE '; VOUT)

OTHER VARTABLES USED IN THTS PROGRAM ARE:

(' ELECTRICAL: ';' HFE = ';HFE;' DRIVERESISTANCE = ';RES;' [OHMS] ')

[84] (' PEAK CURRENT = ';IMAX;'[AMPS] ';'NUMBER OF PRTMARY TURNS = I;NP)

[BЬ] (' NUMBER OF SECONDARY TURNS = ':NSEC;' Q OF PICK UP COIL = ';R)

[86] (' WUMBER OF TURNS IN PICK UP WINDING $=1 ; N S$ )

[B7] (' MAGNETIC: ';' PEAK MAGNETIC EIELD,H=';HMAX; '[OERSTEDS] ')

[88] (' PEAK INDUCTION = ';BMAX;'[GAUSS] ';', SATURATION PERMEABILITY ';MUSAT;'[GAUSS/OERSTED]')

[89] (' INDUCTION AT SATURATION = ';BSAT;'[GAUSS] COERCTVE FORCE ' ';HC;'[OERSTEDS]')

[90] (' DIFFERENTIAL PERMEABILITY =';MUDEL;'[GAUSS/OERSTED] FIELDAT SATURATION =';HSAT;'[OERSTEDS]')

[91] (' MU-SUB-ZERO = ';MU1[;1];'[GAUSS/OERSTED]')

$\nabla M O C O N[U] \nabla$

$\nabla M O C O N$

[1] $\quad M U+14500$

$[2] \quad$ A THIS FOR 2 DIMEW $C Y L(\nabla . B=0)$
$[3] \quad H E+H[L] \div\left(1+M U \times\left(L D *\left(\begin{array}{c}1.72 \\ 1\end{array}\right)\right)\right.$

$\nabla$

$H E \leftarrow-H[L] \times 2 \times(B D \star 2) \times(1+(A D \div B D) * 2) \div(M U \times((A D \star 2)-B D * 2))$

$\nabla N I \operatorname{CON}[\mathrm{D}] \mathrm{D}$

$\nabla N I C O N$

[1] $M U \leftarrow 560$

[2] $H E+H[L] \div(1+M U \times(L D *-1.72))$ 
$\nabla N I D A T A[\square] \nabla$

$\checkmark N I D A T A$

[1] 'DATA FOR DELTAMAX AT 100KHZ'

$B S A T+14500$

$\mathrm{HC}+0.8$

$M U D E L+30000$

$H S A T+(B S A T+B C \times M U D E L) \div M U D E L$

MUSAT+400

$B M A X+B S A T+($ HMAX $\rightarrow H S A T) \times M U S A T$

'ENTER PEAK FLUX IN MAXWELLS

$P H I M A X+\square$

[10]' ('CROSS SECTION AREA IS I:PHIMAX+BMAX)

[11] $A+P H I M A X+B M A X$

$\nabla$

$\nabla M O P O W[\square] \nabla$

$\nabla$ MOPOW

$M U+14500$

$K \leftarrow(M U D E L \div M U) * 1 \div 0.05$

$P 1 \leftarrow 0$

$H E+H[L] \div 10$

$P 11: H T \leftarrow H E$

$M U \leftarrow((H E \leq 0.05) \times 14500 \times K * H E)+(H E>0.05) \times M U D E L$

$H E * H[L] \div(1+M U \times(L D *(-1.72)))$

$H E+(H T+H E) \div 2$

$\rightarrow(((\mid(H E-H T) \div H E)>0.01 \times H E) \times(H E \times 0)) / P 11$

$\nabla H I P O W[U] \nabla$

$\nabla N I P O W$

$P 1+0$

$K+(M U D E L \div M U) * 1 \div 0.38$

$H E+H[L] \div 10$

$P 11: H T+H E$

$\begin{aligned} & P 11: H T+H E \\ & M U+((H E \leq 0.38) \times 560 \times K * H E)+(H E>0.38) \times M U D E L\end{aligned}$

$H E+H[L] \div(1+M U \times(L D *(-1.72)))$

$H E+(H T+H E) \div 2$

$\nabla$

$\rightarrow(((\mid(H E-H T) \div H E)>0.01 \times H E) \times(H E \neq 0)) / P 11$ 
DMODATA[U]D

MODATA

'DATA FOR 4-79 MO PERMALLOY AT $100 \mathrm{KHZ}$

[2] BSAT+6000

[3] $\quad H C+0.15$

[4] MUDEL +50000

[5] HSAT+(BSAT+HC $\times M U D E L) \div M U D E L$

[6] MUSAT+100

[7] BMAX+BSAT+( HMAX-HSAT) $\times M U S A T$

[8] 'ENTER PEAK FLUX IN MAXWELLS'

[9] PHIMAX $+\mathrm{L}$

[10] ('CROSS SECTION AREA IS ':PHIMAX $\div B M A X ;$ '[CM*2]')

[11] $A+P H I M A X \div(B S A T \times(1+0.04))$

VHAGLIN[U]

$\nabla$ SC MAGLIN $X$

[1] $\because 1$

[2] $\because 3$

[4] 'THIS IS A CALCULATION OF PERCENTAGE DEVIATION FROM A LEAST SQUARES FITTED STRATGHT LINE'

[5] ('SERIAL NUMBER ';SC[1],SC[2])

[6] ('CHANNEL ';SC[3])

[8],

$[9] \quad X$

$[10] \quad Y+\left(\begin{array}{llllllllllll}5 & 4 & 3 & 2 & 1 & 0 & -1 & -2 & -3 & -4 & -5\end{array}\right) \times 100$

$[11] \quad Z B A R++/ X \div \rho X$

$\left[12^{2}\right] \quad Y B A R++/ Y \div \rho Y$

[13] $B \leftarrow+/((X-X B A R) \times Y) \div+/((X-X B A R) \times(X-X B A R))$

[14] $B 1+1000 \div B$

[15] ('THE WUMBER OF VOLTS PER OERSTED IS ';B1)

[16] $A+Y B A R-B \times X B A R$

[17] $Z \leftarrow A \div B$

[18] ('THE ZERO OFESET IN VOLTS IS $1 ; Z)$

[19] $L+(X+Z) \times B$

[20] $P+(y-L) \div 5$

[21] $A E+(+/ \mid P) \div \circ P$

[22] ('AVERAGE ABSOLUTE ERROR IS ';AE;' PERCENT')

[23] $\because$

[24] 'THE FOLLOWING IS A PLOT OF ERROR IN PERCENT VS THE MAGNETIC FIELD IN MILLIOERSTEDS'

$[25] 70 \quad 70$ PLOT $P$ VS $Y$ 
$\nabla S K L I N[G] \nabla$

$\nabla S K L I N$

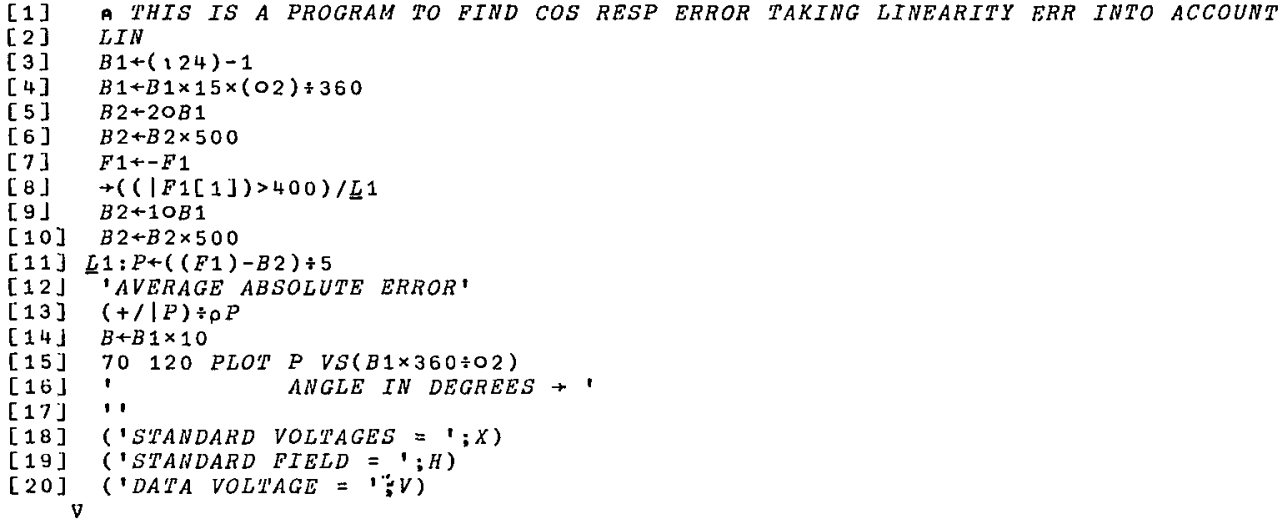

$\nabla L I N[0] \nabla$

$\nabla \quad L I N ; N ; S P A$

[1] A 'THIS IS A PROGRAM TO REMOVE LINEARTTY ERROR'

[2] $F 1+4000$

- EWTER the VOLTAGES TO BE USED AS A STANDARD FOR CALIBRATION

$X+\lfloor]$

'ENTER THE MAGNETTC FIELDS CORRESPONDTNG TO TIESE VOLTAGES ,

$H+L$

ENTER THE VOLTAGES TO BE CONVERTED INTO FIELDS BASED ON

TUE ABOVE AS A STANDARD

$[8] \quad V \leftarrow[]$

$[9] \quad X+X, X[\rho X]+(X[\rho X]-X[((\rho X)-1)])$

$[10] X I+(2 \times X[1])-X[2]$

[11] $X+X I, X$

[12] $\quad H+H, H[\rho H]+(H[\rho H]-H[((\circ H)-1)])$

$[13] H I+(2 \times H[1])-H[2]$

$[14] H+H I, H$

[15] $\quad N+0$

[16] $N+N+1$

$[171 \quad M++/(V[N]<X)$

[18] $M 1+M+1$

$[19] \quad F 1[N]+((V[N]-X[M]) \times(H[M 1]-H[M]) \div(X[M 1]-X[M]))+H[M]$

$[20] \rightarrow 16 \times 1(N<\rho V)$

[21] 'ACTUAL $F$ MEAS'

[22] $(0 \neq F 1) / E 1$

[23] $F 1+(0 \neq F 1) / F 1$ 


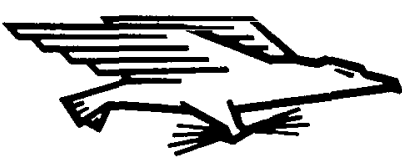

POSTAGE AND FEES PAID NATIONAI AERONAUTICS AND SPACE ADMINISTRATION

"The aeronatitical and space activities of the United States shall be conducted so as to contribute. . . to the expansion of buman knouledge of phenomena in the atmospbere and space. The Administration shall provide for the widest practicable and appropriate dissemination of information concerning its activities and the results thereof."

- National Aeronautics And Space ACt of 1958

\section{NASA SCIENTIFIC AND TECHNICAL PUBLICATIONS}

TECHNICAL REPORTS: Scientific and technical information considered important, complete, and a lasting contribution to existing knowledge.

TECHNICAL NOTES: Information less broad in scope but nevertheless of importance as a contribution to existing knowledge.

TECHNICAL MEMORANDUMS: Information receiving limited distribution because of preliminary data, security classification, or other reasons.

CONTRACTOR REPORTS: Scientific and technical information generated under a NASA contract or grant and considered an important contribution to existing knowledge.
TECHNICAL TRANSLATIONS: Information published in a foreign language considered to merit NASA distribution in English.

SPECIAL PUBLICATIONS: Information derived from or of value to NASA activities. Publications include conference proceedings, monographs, data compilations, handbooks, sourcebooks, and special bibliographies.

TECHNOLOGY UTILIZATION PUBLICATIONS: Information on technology used by NASA that may be of particular interest in commercial and other non-aerospace applications. Publications include Tech Briefs, Technology Utilization Reports and Notes, and Technology Surveys.

Details on the availability of these publications may be obtained from:

$$
\text { SCIENTIFIC AND TECHNICAL INFORMATION DIVISION }
$$

NATIONAL AERONAUTICS AND SPACE ADMINISTRATION Washington, D.C. 20546 